\title{
USING ACCESSIBILITY MEASURES IN TRANSIT NETWORK DESIGN
}

\author{
Gorkem Gulhan $^{1}$, Huseyin Ceylan ${ }^{2}$, Halim Ceylan ${ }^{3}$ \\ ${ }^{1}$ Dept of Urban and Regional Planning, Faculty of Architecture and Design, \\ Pamukkale University, Denizli, Turkey \\ ${ }^{2,3}$ Dept of Civil Engineering, Faculty of Engineering, Pamukkale University, Denizli, Turkey
}

Submitted 22 January 2015; resubmitted 12 August 2015, 17 November 2015, 26 February 2016; accepted 31 March 2016; published online 12 April 2017

\begin{abstract}
Transit planning scenarios may lead to the different Objective Function (OF) values since each scenario has different transit travel times, frequencies and fleet sizes. Change on those variables leads to the different accessibility values for each route set. Therefore, the actual performance of a route set may be unforeseen since the accessibility values are out of evaluation criteria. This study tries to generate techniques, which handle the relation between accessibility and transportation in the scope of public transit. The accessibility measures, which have direct relation with land use and transportation, are utilized in transit route set decision. Accessibility measures have been utilized in the decision-making process of transit network design. Conventional OFs, which are used to determine the most effective route sets are combined with accessibility based OFs and the decision-making process of transit network design is strengthened. In this context, the effects of accessibility measures in decision-making process of transit network design have been represented on an 8-node example transit network. The results showed the accessibility measures could effectively improve the planners' decision accuracy.
\end{abstract}

Keywords: transit network design; potential accessibility; utility-based accessibility; spatial interaction; transit assignment; multi-criteria decision-making.

\section{Introduction}

Spatial interaction between land use and transportation is an ever-developing concept since the literature about the scope is not fully formed yet (Geurs, Ritsema van Eck 2001). Accessibility is a vital parameter of land use and transportation interaction, however it is still evolving. Concept of accessibility has gained importance since it may be utilized in several stages of transportation planning in which the conventional paradigms have lost their efficiency. Transit network design problem, which directly affects the urban accessibility level, is a significant part of transportation planning. Public transportation systems are presented in most of the cities in the world, either conceived as a service that should be provided to the inhabitants as a tool for urban planning or as business of private companies (Cancella et al. 2015).

Accessibility is a significant issue, which has been used in many fields such as transportation and urban planning. Accessibility as a concept may be defined and measured in several methods by several researchers. Accessibility index is defined as the ease of people to reach the desired facilities, products and activities (Bhat et al.
2000). It has a considerable potential for the application in travel demand models since it is focused on the main purpose and expected utility of transportation activities. The mostly used definitions for the accessibility are; the potential of opportunities for interaction (Hansen 1959), the ease with which any land-use activity can be reached from a location using a particular transport system (Dalvi, Martin 1976), the freedom of individuals to decide whether or not to participate in different activities (Burns 1979) and the benefits provided by a transportation/land-use system (Ben-Akiva, Lerman 1979). Even if there are several studies regarding the definition of the accessibility; the basic spine of the concept is similar in terms of components, measures and perspectives (Gulhan et al. 2013). Land-use, transportation, temporal and individual components are the main elements of accessibility components that planners utilize and specify as an origin for getting into accessibility measures (Geurs, Ritsema van Eck 2001). Infrastructure-based, personbased, Utility-Based Accessibility (UBA) and the Potential Accessibility (PA) measures have been improved to determine the performance of accessibility (Geurs, Van Wee 2004). 
The previous transit-oriented studies have considered the accessibility measures as the methodology and perspective while it is possible to utilize as an efficiency indicator (Pitot et al. 2006; Benenson et al. 2010; Curtis 2011; Mavoa et al. 2012). Measuring the efficiency of transit performance is essential since it enables planners to evaluate and compare the success of individual operators (Costa, Markellos 1997). Additionally, possible effects of a change on the transit system may not be reflected by merely evaluating conventional indicators and it may cause inaccurate decisions (Gulhan et al. 2014). Thus, it is important to measure the level of accessibility provided by public transit alternatives in order to support the decision-making process of the public transit planning (Lei, Church 2010).

The studies about the transit network design problem are widely focus on determining frequencies, intervals and spaces. The researches about network design algorithms at 1960s and 1970s are given in detail by Axhausen and Smith (1984). Methods on determining bus routes (Hobeika, Chu 1979), synchronous design of frequencies and routes (Marwah et al. 1984), maximizing amount of trip by setting routes without transfer (Van Nes et al. 1988), generating optimum service plans at the level of sketch (List 1990) have been developed. Common approaches for the solution of the transit network design problem are GIS utilization (Ramirez, Seneviratne 1996), determining route choice and frequencies in the basis of genetic algorithms (Pattnaik et al. 1998; Bielli et al. 2002; Tom, Mohan 2003), and optimization of the interaction between bus service level and trip demand (Yan, Chen 2002). Transit network design models can be categorized as analytical and network models. Network models based on nodes and links do not require spatial data (Kuah, Perl 1989). However, analytical models require spatial data (Wirasinghe 1980; Wirasinghe et al. 1977; Kuah, Perl 1988; Chien, Schonfeld 1998; Chien, Yang 2000; Chien et al. 2001). Ibarra-Rojas et al. (2015) has reviewed the literature on the planning, operation, and control of the bus transport networks. The planning process involves every decision that should be taken before the operation of the system, and it is known as the Transit Network Planning (TNP) problem. Due to its complexity, TNP is commonly divided into the following sub-problems: transit network design, frequency/timetable setting, vehicle scheduling and crew planning. Note that the solution of those problems requires tactical, strategic and operational decisionmaking (Desaulniers, Hickman 2007).

Ceder (2007) states that there are two approaches for generating transit routes: for a set of routes or a small set of routes at a level of network. Those approaches generate several Objective Functions (OFs), which are procured by several perspectives and criteria that evaluate passengers, operations and relevance of society. Those perspectives and criteria have been created by Israeli and Ceder (1995), Ceder (2001, 2002) and Yin et al. (2005). There are mainly three perspectives: passengers, operator and community. Ceder (2007) defines four criteria while measuring the efficiency of a transit route: mini- mum waiting time for a passenger (passenger perspective), minimum empty seat/space time (operator perspective), minimum time difference from shortest path (passenger and community perspective) and minimum fleet size (operator perspective). It is also stated that the TNP problem may be dealt with different algorithms such as heuristic algorithms, integer-programming optimization, nonlinear programming using relaxation methods instead of enumeration of all possible covering scenarios. Note that the outcome of all algorithms is a set of a minimum number of routes that cover all Origin-Destination $(\mathrm{O}-\mathrm{D})$ pairs in the network.

Although both accessibility formulations and network design techniques have already been used before, there is still a significant gap in using accessibility measures in decision stages of transit network design. This study tries to make a contribution to the current state of the art on the decision level of transit network design by using accessibility measures as OFs in decision-making process. For that purpose, conventional OFs have been calculated and decision-making process is supported with PA and UBA measures. In the proposed methodology, optimal transit network design is determined by employing multi-criteria decision analysis between conventional and accessibility measures.

The general structure of the study has been organized as follows: the current transit features of the study network and methodology are defined in the first section. Accessibility and transit network design analyses are provided in the second section. Last section is the part for the general evaluations.

\section{Methodology}

This study tries to further extend the transit network design approach of Ceder (2007) by utilizing the PA and UBA measures. Transit network design process and accessibility measures have been integrated in an analytical process, which consists of six steps as given in Fig. 1.

As can be seen in Fig. 1 that transit demand between $\mathrm{O}-\mathrm{D}$ pairs, terminals, nodes, links and the average travel times are initialized. Then the bus routes, which start from terminals are enumerated and the travel times of the shortest paths are calculated. At Step 1, several possible routes may be eliminated by using route lengths and travel time constraints in order to prevent excessive number of routes to be considered. Note that the demand is neglected at this stage.

At Step 2, possible route sets, which have to provide accessibility to each node, are generated. Note that the transit users may reach their destinations directly on a particular bus route or through a terminal to select a second route.

At Step 3, transit assignment is carried out to calculate passenger volumes on bus routes and minimum required service frequencies. Note that the demand is assigned on the transit routes with shortest travel time between the related O-D pairs. In other words, the transit users' strategy is established to minimize total waiting time at stops, transfers and in vehicles. After the assignment process, frequencies on routes are obtained. Then 


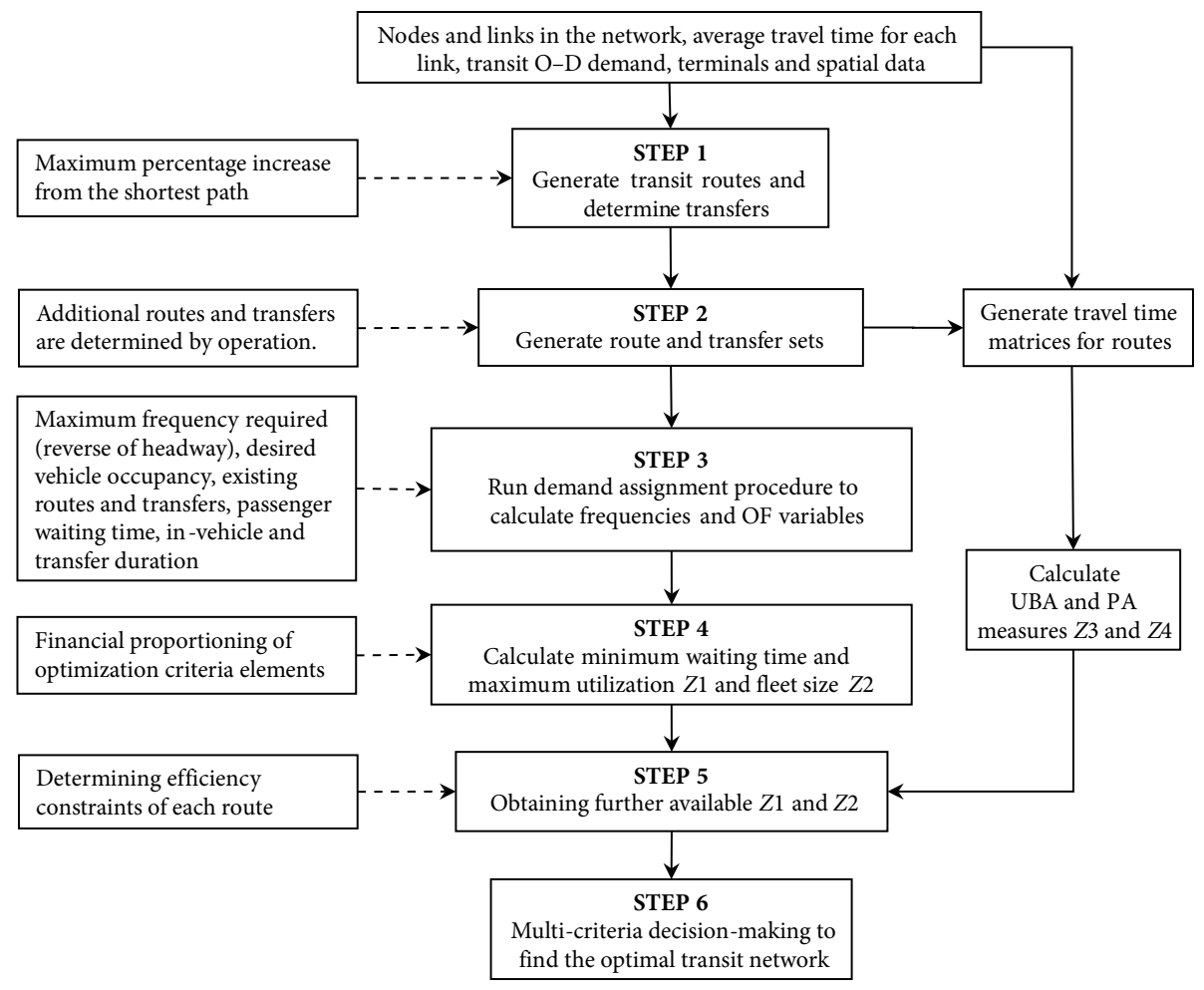

Fig. 1. Flowchart of the proposed transit network design approach

the passenger volumes and frequencies are used to calculate the OFs.

At Step 4, two OFs are defined: $Z 1$ represents total waiting time and utilization of transit users, $Z 2$ is the fleet size. $Z 1$ consist of five different OFs. The first one is the total waiting time to be minimized as a user perspective as given in Eq. (1):

$$
\min a_{1} \sum_{i, j \in N} W T(i, j)
$$

where: $a_{1}$ is fiscally equivalent of one hour waiting time.

The second objective tries to minimize the amount of unused seats as an operator perspective as given in Eq. (2):

$$
W_{r}=\frac{1}{2 F_{r}}
$$

where: $W_{r}$ represents passenger waiting time on route $r$; $F_{r}$ represents the vehicle frequency on route $r$.

Formulation of the third objective is given in Eq. (3):

$$
\sum_{i, j \in N} W T(i, j)=\sum_{r \in R} \frac{1}{2 F_{r}}\left(\sum_{i, j \in N_{r}} d_{i j}^{r}+\sum_{i, j \in N_{t r}} d_{i j}^{t r} a_{t r}^{r}\right),
$$

where: $R$ represents transit route set; $r$ is specific route; $N_{t r}$ is node set on the transfer path $t r ; N_{r}$ is the node set in route $r$; $d_{i j}^{r}$ is the travel demand between $i$ and $j$; $a_{t r}^{r}$ is a binary variable that indicates whether transfer $t r$ moves through route $r$ or not; $d_{i j}^{\text {tr }}$ is the travel demand between $i$ and $j$ along the transfer path $t r$.

Meanwhile, if $a_{t r}^{r}=1$ then $t r$ transfer exists on route $r$, otherwise there is not any transfer on route $r$.
The fourth objective is given in Eq. (4):

$$
E H_{r}=\left(\max \left(L_{r}, F_{\min }, d_{o}\right)\right) t_{r}-\sum_{i, j \in N} P H(i, j),
$$

where: $L_{r}$ represents maximum passenger load on route $r ; F_{\min }$ is the minimum required frequency; $d_{o}$ is desired occupancy in each vehicle (loading standard); $t_{r}$ is total travel time on route $r$.

Eq. (5) represents the last objective of $Z 1$ that represents the proximity to the shortest path:

$$
\sum_{i, j \in N} D P H(i, j)=\sum_{i, j \in N} P H(i, j)-\sum_{s p \in S} \sum_{j \in N_{s p}} d_{i j}^{s p} t_{i j}^{s p},
$$

where: $d_{i j}^{s p}$ represents the transit demand between $i$ and $j$ along the shortest path; $t_{i j}^{s p}$ is the average travel time of the shortest path between $i$ and $j ; S$ is the set of all shortest paths; $N_{s p}$ is the cluster of nodes which takes place on the shortest path $s p$.

Eq. (6) is the lower function:

$$
\sum_{i, j \in N} P H(i, j)=\sum_{r \in R i, j \in N_{r}} d_{i j}^{r} t_{i j}^{r}+\sum_{t r \in T R} \sum_{i j \in N_{t r}} d_{i j}^{t r} t_{i j}^{t r},
$$

where: $d_{i j}^{\text {tr }}$ is the transit demand between $i$ and $j$ along the transfer path $t r ; t_{i j}^{t r}$ is the average travel time between $i$ and $j$ on transfer path $t r$ and on route $r$ (includes transfer penalties); $t_{i j}^{r}$ is the average travel time between $i$ and $j$ on route $r ; d_{i j}^{r}$ is the transit demand between $i$ and $j$ on route $r ; T R$ is the set of all transfer paths.

Optimization criteria are represented from the point of passengers, operator and the society. At this stage, two OFs are evaluated as $Z 1$ and $Z 2 . Z 1$ function consists of waiting times, empty seat hours and lower level variables of shortest paths. Transit network design 
problem has been established those two OFs as the minimization of $Z 1$ and $Z 2$. The OF used for a single group is given in Eq. (7):

$$
Z 1=a_{1} \sum_{i, j \in N} W T(i, j)+a_{2} \sum_{r} E H_{r}+a_{4} \sum_{i, j \in N} D P H(i, j) .
$$

OFs for comparison are given in Eqs (8) and (9):

$$
\begin{aligned}
& Z 1=a_{1} \sum_{i, j \in N} W T(i, j)+a_{2} \sum_{r} E H_{r}+ \\
& \sum_{i, j \in N}\left(a_{3} P H(i, j)-a_{4} D P H(i, j)\right) ; \\
& Z 2=F S .
\end{aligned}
$$

In Eq. (8), $P H(i, j)$ represents passenger-kilometres between $i$ and $j(\forall i, j \in N)$ (it is defined as the travel time of passengers in vehicle on hourly basis; measures the time spent between two nodes). $D P H(i, j)$ represents the shortest path difference in passenger-kilometres. $W T(i, j)$ is the waiting time between nodes $i$ and $j(\forall i, j \in N)$ (defined as the time which passengers spend on the bus stops between two nodes). $E H_{r}$ is the empty seat hours on route $r$ (defined as the unused seats and represents the unused capacity in vehicles). FS represents the fleet size (amount of vehicles used for transit service), $a_{k}$ represents fiscal coefficient or the other proportions in the form of $k=1,2,3,4$.

Operation interests are evaluated in three perspective as fleet size, empty-seat hour and length of routes. Primarily, fleet size is the most significant operation perspective OF of $Z 2$ represents the fleet size. Consequently, as the fleet size get decreased the general efficiency increase in the algorithm. Increasing vehicle quantity inclines a purchase or a hire cost, thus operation interest is about minimizing the total vehicle quantity.

Length of routes may be considered as the second lower objective. Mentioned objective is provided in the section of route generation. The maximum deviation from the shortest path is $\alpha-0.4$. It means that no route length or portion of it can exceed its associated shortest travel time by more than $40 \%$. Operation expects to decline its fuel costs, salaries, working times and vehicle aging.

At Step 5, the minimum $Z 1$ and $Z 2$ values are searched among the route sets and $Z 3$ and $Z 4$ values, which represent the PA and UBA measures, are calculated. PA is expressed as the total PA values of all zones as given in Eq. (10):

$$
P A=\sum_{i} A_{i}=\sum_{i} \sum_{j} \frac{D_{j}}{d_{i j}^{\gamma}}
$$

where: $A_{i}(\mathrm{ha} / \mathrm{min})$ represents the accessibility measure to opportunities $D_{j}$ of zone $i ; d_{i j}^{\gamma}$ is the impedance factor between $i$ and $j$ and $\gamma$ is the parameter, which represents the impedance of the distance.

UBA values are calculated for all cases by using Eq. (11):

$$
U B A=\sum_{i} A_{i}=\sum_{i} \frac{1}{\beta} \ln \sum_{j} \frac{D_{j}}{e^{\beta c_{i j m}}},
$$

where: $A_{i}$ represents the accessibility for the $n$ individual in zone $i$, at transportation mode $m$, with a cost $c_{i j m}$. It can also be defined as the achieved utility from opportunities $D_{j}$ at zone $j$.

The sixth step of the methodology involves investigating the most efficient route sets by utilizing multiobjective evaluation of transit network design decisions using OF pairs. Thus, policy makers may take incisive decisions by analysing the correlation between $Z 1$ and $Z 2$. With addition of $Z 3$ and $Z 4$ functions, public welfare may be better reflected in decision-making process of transit planning.

\section{Transit Network Design Analyses}

In this section, the proposed transit network design approach is applied to the study network which is illustrated based upon the one used by Ceder (2007). The layout of the 8-node bus network is given in Fig. 2.

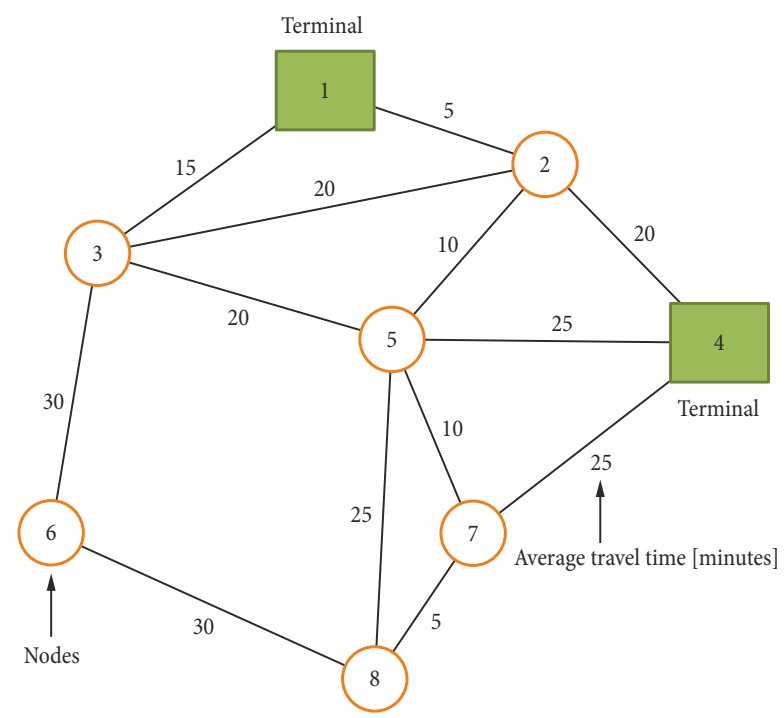

Fig. 2. Layout of the study network (Ceder 2007)

In the study network, the nodes have been accepted as centroids, consequently transit demand between nodes represent the travel demand between zones. Total transit demand for the network is given in Table 1.

Table 1 indicates that the sixth and eighth zones attract higher demand. The first and fourth nodes are considered as terminals. Average travel times between nodes are given in Table 2.

Table 1. Demand between the nodes [person] (Ceder 2007)

\begin{tabular}{|c|c|c|c|c|c|c|c|c|}
\hline Nodes & 1 & 2 & 3 & 4 & 5 & 6 & 7 & 8 \\
\hline 1 & & 80 & 70 & 160 & 50 & 200 & 120 & 60 \\
\hline 2 & & & 120 & 90 & 100 & 70 & 250 & 70 \\
\hline 3 & & & & 180 & 150 & 120 & 30 & 250 \\
\hline 4 & & & & & 80 & 210 & 170 & 230 \\
\hline 5 & & & & & & 250 & 40 & 130 \\
\hline 6 & & \multicolumn{7}{|c|}{ Symmetrical } \\
\hline 7 & & & & & & & 130 & 120 \\
\hline 8 & & & & & & & & 70 \\
\hline
\end{tabular}


Table 2. Average travel times between nodes [min] (Ceder 2007)

\begin{tabular}{|c|c|c|c|c|c|c|c|c|}
\hline Nodes & 1 & 2 & 3 & 4 & 5 & 6 & 7 & 8 \\
\hline 1 & & 5 & 15 & & & & & \\
\hline 2 & 5 & & 20 & 20 & 10 & & & \\
\hline 3 & 15 & 20 & & & 20 & 30 & & \\
\hline 4 & & 20 & & & 25 & & 25 & \\
\hline 5 & & 10 & 20 & 25 & & 35 & 10 & 25 \\
\hline 6 & & & 30 & & 35 & & & 30 \\
\hline 7 & & & & 25 & 10 & & & 5 \\
\hline 8 & & & & & 25 & 30 & 5 & \\
\hline
\end{tabular}

By following the flowchart given in Fig. 1 for the proposed approach, some detailed illustrative steps are provided as:

Step 1: all possible routes for the transit network have been enumerated under several assumptions and constraints (Ceder 2007). A travel in other words a route has been accepted as valid only if it starts from a terminal. Maximum distinction from the shortest path has been accepted as $40 \%$, which means $\alpha$ has been determined as 0.4. Relevant routes after elimination, accessible nodes and travel times for mentioned routes are showed in Table 3.

Step 2: alternative route sets have been generated to obtain $Z 1$ and $Z 2$ functions which have been given in Eqs (8) and (9). As a matter of fact, each route set is a unique scenario. A route set may consist of all possible routes. Consequently, maximum number of routes in a route set has been limited to six and the transfers have been neglected. Note that the route sets have to provide access to each node in the network. By evaluating emphasized constraints, 19538 route sets have been obtained for study transit network. If the amount of nodes increase in a network then the amount of route sets have a major increase. In such cases, Ceder (2007) has been proposed several optimization techniques

Step 3: assignment of transit demand has been carried out to calculate the number of passenger journeys occur on the bus routes. Note that the demand is assigned on transit routes with shortest travel time between the related O-D pairs. Vehicle capacity in the network has been accepted as $d_{o}=50$. Passenger-load profile has been generated for each route and vehicle frequencies have been obtained from those passengerload profiles.

Step 4: Lower level variables of $Z 1$ have been accepted as $a_{k}=1$ and $k=1,2,3,4$. At the calculation of $D P H(i, j)$, travel times for private car mode between nodes have been used. Pre-defined travel times are given in Table 4.

$Z 1$ values have been calculated for each possible route and their values are given in Table 5 .

$Z 1$ values have been found by gathering $P H_{r}, D P H_{r}$, $W H_{r}$, and $E H_{r}$ which are found for each route. Minimum fleet sizes, in other words, $Z 2$ values have been found for all routes. Maximum load, frequencies and empty-seat hour have been calculated. $\mathrm{PH}_{r}$ and $D P H_{r}$ values have been found.
Minimum frequencies have been obtained by dividing the load of maximum demands to vehicle capacities after calculation of $Z 1$ function values. Afterwards, minimum fleet size values, in other words $Z 2$ values, have been. Due to fleet size cannot be a fractional number, vehicle quantities have been finalized to nearest integer values. The 10 most efficient $Z 1$ values with fleet size is given in Table 6 .

Step 5: $Z 1$ and $Z 2$ values have been enumerated, afterwards $Z 3$ and $Z 4$ values are calculated. The minimum $Z 1$ value is 10402 passenger-kilometre and it has been generated by route set 5 , which includes the routes 6 and 34. The maximum $Z 1$ value is 45600 passengerkilometres and it has been generated by route set 19427 , which includes the routes 23, 24, 27, 28, 29 and 32. Z1 function has been calculated for each route set and the 10 most efficient $Z 1$ values are given in Table 7 .

The 10 most efficient $Z 1$ values are between 10000 passenger-kilometres and 13000 passenger-kilometres $Z 1$ values for those route sets are $5,1,7,2,79,11,22$, 303, 287 and 3.

In accessibility calculation process, each route set has been determined as a scenario. Each scenario has different accessibility values since each scenario has different travel time matrices. Passengers who travel between zones/nodes have to change terminals/routes, if there is no direct access to destination. Therefore, it is supposed that there is a different transportation mode apart from transit network between zones 1 and 4, which has a travel time of 5 minutes. Residential areas have been supposed and showed in Table 8 .

Table 9 shows that areal sizes for zones verify between 100 ha and 456 ha. 10 most efficient PA and UBA values for route sets have been calculated and showed in Table 9.

The route set which provides the maximum PA is the route 6095 with $732 \mathrm{ha} / \mathrm{min}$ and the route set which provides the minimum PA is the route 3479 with $370 \mathrm{ha} / \mathrm{min}$. Note that, accessibility values do not involve categoricalness and they are generated values for internal comparison since it is not significant to positive or negative. Table 9 indicates that PA values have more inherent distinction than UBA values. While PA values verify between 732 and 724, UBA values verify in a smaller interval. Accessibility values are index values and they are meaningful when they are compared with each other. Consequently, it is a regular circumstance for UBA values to be negative.

Step 6: Optimal design method of the proposed approach involves investigating the most efficient route sets by utilizing multi-objective evaluation of transit network design decisions using $O F$ pairs. The purpose is to investigate the various alternatives for the most efficient $(Z 1, Z 2)$ solution. Therefore, the decision-maker can decide whether or not to accept the proposed solution; for example, the decision-maker can see how much $Z 1$ is increased by decreasing $Z 2$ to a certain value, and vice versa (Ceder 2007). The trade-off between $Z 1$ and $Z 2$ is investigated using a two-dimensional graph given in Fig. 3. 
Table 3. Possible routes in the study network (Ceder 2007)

\begin{tabular}{|c|c|c|c|c|c|c|c|}
\hline Routes & \multicolumn{6}{|c|}{ Nodes } & Travel time [min] \\
\hline 1 & 1 & 2 & & & & & 5 \\
\hline 2 & 1 & 3 & & & & & 15 \\
\hline 3 & 1 & 2 & 4 & & & & 25 \\
\hline 4 & 1 & 2 & 5 & & & & 15 \\
\hline 5 & 1 & 3 & 6 & & & & 45 \\
\hline 6 & 1 & 2 & 3 & 6 & & & 55 \\
\hline 7 & 1 & 2 & 5 & 6 & & & 50 \\
\hline 8 & 1 & 2 & 5 & 7 & & & 25 \\
\hline 9 & 1 & 2 & 5 & 7 & 8 & & 30 \\
\hline 10 & 1 & 2 & 5 & 8 & & & 40 \\
\hline 11 & 4 & 2 & 1 & & & & 25 \\
\hline 12 & 4 & 2 & & & & & 20 \\
\hline 13 & 4 & 5 & 2 & 1 & 3 & & 55 \\
\hline 14 & 4 & 5 & 3 & & & & 45 \\
\hline 15 & 4 & 2 & 3 & & & & 40 \\
\hline 16 & 4 & 7 & 5 & 3 & & & 55 \\
\hline 17 & 4 & 5 & 2 & 3 & & & 55 \\
\hline 18 & 4 & 2 & 1 & 3 & & & 40 \\
\hline 19 & 4 & 2 & 5 & 3 & & & 50 \\
\hline 20 & 4 & 5 & & & & & 25 \\
\hline 21 & 4 & 2 & 5 & & & & 30 \\
\hline 22 & 4 & 5 & 6 & & & & 60 \\
\hline 23 & 4 & 5 & 7 & 8 & 6 & & 70 \\
\hline 24 & 4 & 2 & 1 & 3 & 6 & & 70 \\
\hline 25 & 4 & 7 & 8 & 6 & & & 60 \\
\hline 26 & 4 & 2 & 5 & 6 & & & 65 \\
\hline 27 & 4 & 2 & 3 & 6 & & & 70 \\
\hline 28 & 4 & 5 & 8 & 6 & & & 80 \\
\hline 29 & 4 & 2 & 5 & 7 & 8 & 6 & 75 \\
\hline 30 & 4 & 7 & 5 & 6 & & & 70 \\
\hline 31 & 4 & 2 & 5 & 3 & 6 & & 80 \\
\hline 32 & 4 & 5 & 3 & 6 & & & 75 \\
\hline 33 & 4 & 7 & & & & & 25 \\
\hline 34 & 4 & 5 & 7 & 8 & & & 40 \\
\hline 35 & 4 & 7 & 8 & & & & 30 \\
\hline
\end{tabular}

Table 4. Travel times for the private car mode between nodes [min]

\begin{tabular}{|c|c|c|c|c|c|c|c|c|}
\hline Nodes & 1 & 2 & 3 & 4 & 5 & 6 & 7 & 8 \\
\hline 1 & & 3 & 10 & 15 & 11 & 20 & 20 & 18 \\
\hline 2 & 3 & & 15 & 15 & 7 & 31 & 18 & 10 \\
\hline 3 & 10 & 15 & & 30 & 11 & 22 & 22 & 11 \\
\hline 4 & 15 & 15 & 30 & & 20 & 30 & 21 & 18 \\
\hline 5 & 11 & 7 & 11 & 20 & & 30 & 9 & 14 \\
\hline 6 & 20 & 31 & 22 & 30 & 30 & & 20 & 20 \\
\hline 7 & 20 & 18 & 22 & 21 & 9 & 20 & & 4 \\
\hline 8 & 18 & 10 & 11 & 18 & 14 & 20 & 4 & \\
\hline
\end{tabular}

Table 5. $Z 1$ values for possible routes [passenger-kilometre]

\begin{tabular}{|c|c|c|c|c|}
\hline Routes & $W T(i, j)$ & $\mathrm{EH}_{\mathrm{r}}$ & $D P H(i, j)$ & $Z 1$ \\
\hline 1 & 3000 & 0 & 111 & 3111 \\
\hline 2 & 3000 & 0 & 173 & 3173 \\
\hline 3 & 3123 & 130 & 517 & 3770 \\
\hline 4 & 4414 & 13 & 285 & 4712 \\
\hline 5 & 3508 & 100 & 504 & 4112 \\
\hline 6 & 3902 & 502 & 730 & 5134 \\
\hline 7 & 4085 & 83 & 598 & 4766 \\
\hline 8 & 4810 & 187 & 325 & 5322 \\
\hline 9 & 4810 & 285 & 364 & 5459 \\
\hline 10 & 4810 & 647 & 644 & 6101 \\
\hline 11 & 4500 & 130 & 517 & 5147 \\
\hline 12 & 3000 & 0 & 407 & 3407 \\
\hline 13 & 4384 & 1593 & 953 & 6930 \\
\hline 14 & 3394 & 1100 & 891 & 5385 \\
\hline 15 & 3725 & 473 & 695 & 4894 \\
\hline 16 & 4455 & 363 & 657 & 5475 \\
\hline 17 & 3909 & 1237 & 957 & 6103 \\
\hline 18 & 4586 & 830 & 691 & 6107 \\
\hline 19 & 4107 & 980 & 977 & 6064 \\
\hline 20 & 3000 & 0 & 495 & 3495 \\
\hline 21 & 4107 & 233 & 581 & 4921 \\
\hline 22 & 3414 & 1272 & 808 & 5494 \\
\hline 23 & 3808 & 3017 & 854 & 7679 \\
\hline 24 & 4586 & 2030 & 1021 & 7637 \\
\hline 25 & 3909 & 893 & 538 & 5340 \\
\hline 26 & 4107 & 887 & 894 & 5887 \\
\hline 27 & 3725 & 1673 & 1026 & 6425 \\
\hline 28 & 3505 & 3788 & 1134 & 8427 \\
\hline 29 & 4389 & 2455 & 940 & 7784 \\
\hline 30 & 4229 & 412 & 574 & 5214 \\
\hline 31 & 4107 & 2180 & 1307 & 7594 \\
\hline 32 & 3596 & 2830 & 1222 & 7648 \\
\hline 33 & 3000 & 0 & 220 & 3220 \\
\hline 34 & 3808 & 887 & 574 & 5269 \\
\hline 35 & 3909 & 83 & 258 & 4250 \\
\hline
\end{tabular}

Table 6. The 10 most efficient $Z 1$ values with fleet sizes

\begin{tabular}{|c|c|c|}
\hline \multirow{2}{*}{$\begin{array}{c}\text { Route } \\
\text { sets }\end{array}$} & $Z 1$ [passenger-kilometre] & $Z 2$ [quantity] \\
\cline { 2 - 3 } & total & vehicle \\
\hline 5 & 10401.81 & 188 \\
\hline 1 & 10957.34 & 140 \\
\hline 7 & 11883.42 & 184 \\
\hline 2 & 11896.08 & 148 \\
\hline 79 & 12190.53 & 183 \\
\hline 11 & 12270.93 & 185 \\
\hline 22 & 12491.48 & 235 \\
\hline 303 & 12787.48 & 266 \\
\hline 287 & 12791.08 & 186 \\
\hline 3 & 12811.81 & 188 \\
\hline
\end{tabular}


Table 7. 10 most efficient $Z 1$ values [passenger-kilometre]

\begin{tabular}{|c|c|c|c|c|c|c|c|c|c|c|c|c|c|}
\hline \multirow{2}{*}{ Route sets } & \multicolumn{6}{|c|}{ Routes } & \multicolumn{6}{|c|}{ Z1 [passenger-kilometre] } & \multirow[t]{2}{*}{ Total $Z 1$} \\
\hline & 1 & 2 & 3 & 4 & 5 & 6 & Route 1 & Route 2 & Route 3 & Route 4 & Route 5 & Route 6 & \\
\hline 5 & 6 & 34 & & & & & 5133 & 5269 & 0 & 0 & 0 & 0 & 10402 \\
\hline 1 & 2 & 29 & & & & & 3173 & 7784 & 0 & 0 & 0 & 0 & 10957 \\
\hline 7 & 9 & 27 & & & & & 5459 & 6424 & 0 & 0 & 0 & 0 & 11883 \\
\hline 2 & 5 & 29 & & & & & 4112 & 7784 & 0 & 0 & 0 & 0 & 11896 \\
\hline 79 & 2 & 7 & 35 & & & & 3173 & 4766 & 4251 & 0 & 0 & 0 & 12191 \\
\hline 11 & 13 & 25 & & & & & 6930 & 5341 & 0 & 0 & 0 & 0 & 12271 \\
\hline 22 & 1 & 5 & 34 & & & & 3111 & 4112 & 5269 & 0 & 0 & 0 & 12491 \\
\hline 303 & 5 & 12 & 34 & & & & 4112 & 3407 & 5269 & 0 & 0 & 0 & 12787 \\
\hline 287 & 5 & 9 & 33 & & & & 4112 & 5459 & 3220 & 0 & 0 & 0 & 12791 \\
\hline 3 & 6 & 23 & & & & & 5133 & 7679 & 0 & 0 & 0 & 0 & 12812 \\
\hline
\end{tabular}

Table 8. Residential areas in the network

\begin{tabular}{|c|c|c|c|c|c|c|c|}
\hline \multicolumn{1}{|c|}{ Residential areas $D$ [ha] } \\
\hline 1 & 2 & 3 & 4 & 5 & 6 & 7 & 8 \\
\hline 125 & 320 & 144 & 456 & 124 & 222 & 100 & 147 \\
\hline
\end{tabular}

As can be seen in Fig. 3 that the compromise solution can be found on the boundary, so-called Pareto front, between route sets 1 and 5, which are more feasible that the other transit network configurations (Coello Coello et al. 2007). At this point, route set 1 requires the smallest fleet for operation while route set 5 provides the minimum waiting time. Therefore, it may be useful to utilize accessibility measures $Z 3$ and $Z 4$ in order to determine the optimal transit network design. Geurs and
Van Wee (2004) stated that the accessibility is a measure for the benefit of society which is represented by transit users. On the other hand, fleet size does not have a common intersection with accessibility measures. Therefore, the trade-off between $Z 1$ and accessibility measures are given in Figs 4 and 5, respectively.

Fig. 4 shows that the route sets 5, 7, 79, 287, 289, 284, 279 and 6095 are on the Pareto front. Based on this trade-off, if the route set 7 is selected as the solution point, the accessibility increases about $11 \%$ while the transit users' benefit decreases about $14 \%$ in comparison with route set 5 . Similarly, if the route set 6095 is selected as the solution point, the accessibility increases about $23 \%$ while the transit users' benefit decreases about $139 \%$.

Table 9. 10 most efficient PA and UBA values for route sets

\begin{tabular}{|c|c|c|c|c|c|c|c|c|c|}
\hline \multirow{3}{*}{$\begin{array}{c}\text { Route } \\
\text { sets }\end{array}$} & \multicolumn{9}{|c|}{ Z3 [ha/min] } \\
\hline & \multicolumn{8}{|c|}{ Zones } & \multirow{2}{*}{ Total } \\
\hline & 1 & 2 & 3 & 4 & 5 & 6 & 7 & 8 & \\
\hline 6095 & 187 & 106 & 64 & 84 & 94 & 35 & 91 & 71 & 732 \\
\hline 6419 & 187 & 106 & 64 & 84 & 94 & 35 & 91 & 71 & 732 \\
\hline 12414 & 187 & 106 & 64 & 84 & 94 & 35 & 91 & 71 & 732 \\
\hline 12743 & 187 & 106 & 64 & 84 & 94 & 35 & 91 & 71 & 732 \\
\hline 13104 & 187 & 106 & 64 & 84 & 94 & 35 & 91 & 71 & 732 \\
\hline 13283 & 187 & 106 & 64 & 84 & 94 & 35 & 91 & 71 & 732 \\
\hline 13626 & 187 & 106 & 64 & 84 & 94 & 35 & 91 & 71 & 732 \\
\hline 12933 & 186 & 106 & 66 & 84 & 96 & 34 & 90 & 70 & 731 \\
\hline 13232 & 186 & 106 & 64 & 84 & 94 & 35 & 91 & 70 & 730 \\
\hline \multirow[t]{2}{*}{13259} & 186 & 106 & 64 & 84 & 94 & 35 & 91 & 70 & 730 \\
\hline & \multicolumn{9}{|c|}{ Z4 [ha/min] } \\
\hline 13173 & 1.654 & -0.141 & -10.124 & -0.155 & -3.955 & -24.322 & -0.004 & -0.395 & -37.44113035 \\
\hline 6142 & 1.654 & -0.141 & -10.124 & -0.155 & -3.955 & -24.322 & -0.004 & -0.395 & -37.44113035 \\
\hline 12461 & 1.654 & -0.141 & -10.124 & -0.155 & -3.955 & -24.322 & -0.004 & -0.395 & -37.44113035 \\
\hline 13325 & 1.654 & -0.141 & -10.124 & -0.155 & -3.955 & -24.322 & -0.004 & -0.395 & -37.44113035 \\
\hline 13331 & 1.654 & -0.141 & -10.124 & -0.155 & -3.955 & -24.322 & -0.004 & -0.395 & -37.44113035 \\
\hline 13170 & 1.654 & -0.141 & -10.124 & -0.155 & -3.955 & -24.322 & -0.004 & -0.395 & -37.44113036 \\
\hline 13415 & 1.654 & -0.141 & -10.124 & -0.155 & -3.955 & -24.322 & -0.004 & -0.395 & -37.44113059 \\
\hline 13416 & 1.654 & -0.141 & -10.124 & -0.155 & -3.955 & -24.322 & -0.004 & -0.395 & -37.44113059 \\
\hline 13161 & 1.654 & -0.141 & -10.124 & -0.155 & -3.955 & -24.322 & -0.004 & -0.395 & -37.44113059 \\
\hline 13191 & 1.654 & -0.141 & -10.124 & -0.155 & -3.955 & -24.322 & -0.004 & -0.395 & -37.44113059 \\
\hline
\end{tabular}




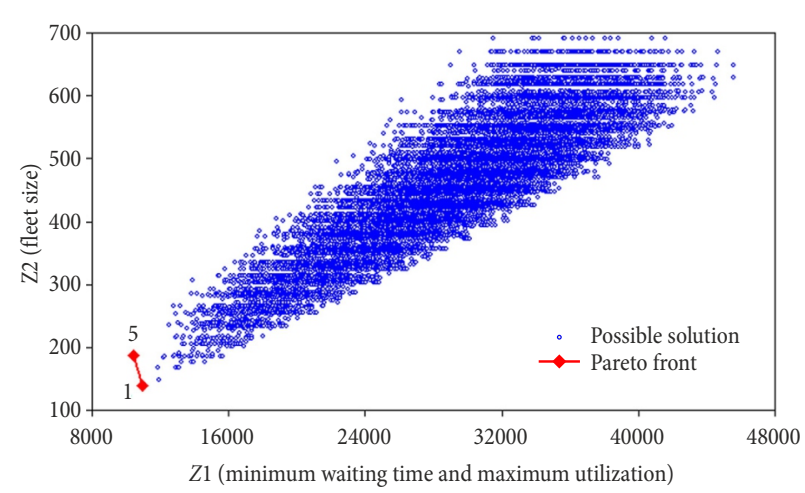

Fig. 3. The trade-off between $Z 1$ and $Z 2$

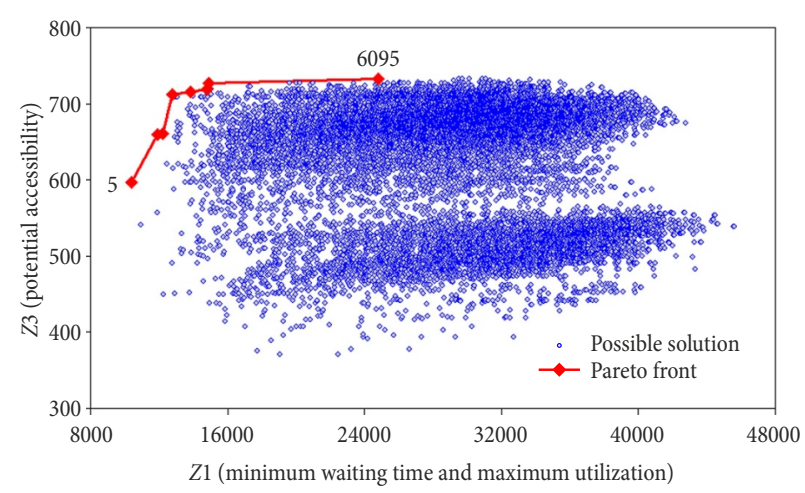

Fig. 4. The trade-off between $Z 1$ and $Z 3$

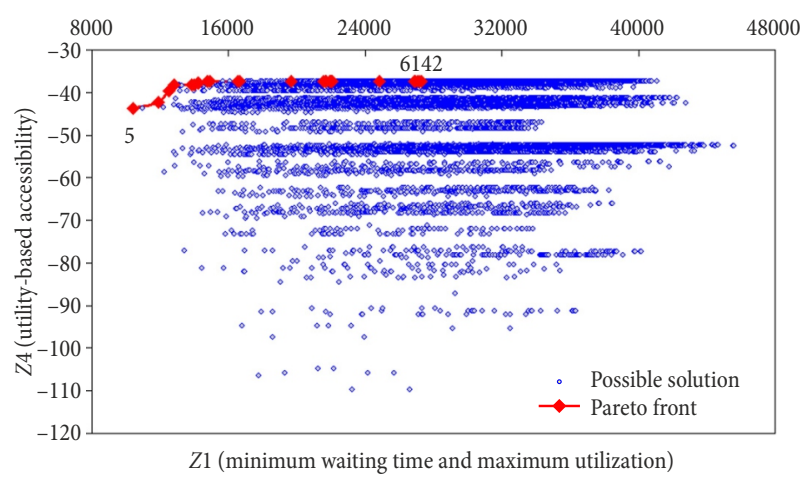

Fig. 5. The trade-off between $Z 1$ and $Z 4$

In Fig. 5, route sets 5, 7, 22, 287, 289, 81, 196, 255, $260,279,256,1780,4640,6139,6131$ and 6142 are on the Pareto front. Based on this trade-off, if the route set 7 is selected as the solution point, the accessibility increases about 3\% while the transit users' benefit decreases about $14 \%$ in comparison with route set 5 . Similarly, if the route set 6142 is selected as the solution point, the accessibility increases about $14 \%$ while the transit users' benefit decreases about $162 \%$. Therefore, the route set 5 may be considered as the best transit network configuration since all other Pareto solutions proportionally reduce transit users' benefit more than the gain in PA and UBA.

\section{Conclusions}

Using accessibility measures in transit network design leads a more comprehensive planning paradigm since spatial interaction values are introduced to general perspective. The reason is that, land use areas and travel times between the zones are participated into design process. In this manner, several transportation characteristics of cities may be utilized without overlooking.

This study aimed to make a contribution to the current state of the art of transit network design by using accessibility measures as OFs in decision-making process. In the proposed methodology, conventional OFs have been calculated and decision-making process is supported with PA and UBA measures. In this context, an example application was provided. Firstly, total travel time and fleet size were calculated on an 8-node example transit network. Pareto solutions for those conventional measures showed that the decision-maker had two route sets that the first one required the smallest fleet for operation while the second one provided the minimum waiting time. While the accessibility measures utilized for the solution, the results showed that the route set with minimum waiting time could be considered as the best transit network configuration since all other Pareto solutions proportionally reduce transit users' benefit more than the gain in PA and UBA.

In this study, the transit demand between the $\mathrm{O}-\mathrm{D}$ pairs is assigned on routes with shortest travel time. Note that those routes were taken from a previous study. In future studies, a timetable-based assignment technique, where all transit services are taken into account with their precise departure and arrival times, may be adopted. Usually, adaptation of algorithms into realworld applications may require high computation times for most engineering optimization problems. However, proposed method did not require high computational efforts since the study network is a small-scaled area for a specific test application.

\section{Acknowledgements}

This study is a part of $\mathrm{PhD}$ dissertation of Dr. Gorkem Gulhan and certain part of the study has been presented at the Congress of TRANSIST'2013 (Turkey).

Authors gratefully acknowledge for the contribution of Dr. Soner Haldenbilen, Dr. Yıldırım Oral, Dr. Serhan Tanyel and Dr. Mert Cubukcu.

\section{References}

Axhausen, K. W.; Smith, R. L. 1984. Evaluation of heuristic transit network optimization algorithms, Transportation Research Record 976: 7-20.

Ben-Akiva, M.; Lerman, S. R. 1979. Disaggregate travel and mobility choice models and measures of accessibility, in D. A. Hensher, P. R. Sopher (Eds.). Behavioural Travel Modelling, 654-679. 
Benenson, I.; Martens, K.; Rofé, Y.; Kwartler, A. 2010. Public transport versus private car GIS-based estimation of accessibility applied to the Tel Aviv metropolitan area, The Annals of Regional Science 47(3): 499-515. https://doi.org/10.1007/s00168-010-0392-6

Bhat, C.; Handy, S.; Kockelman, K.; Mahmassani, H.; Chen, Q.; Weston, L. 2000. Accessibility Measures: Formulation Considerations and Current Applications. Research Report 4938-2. Center for Transportation Research, Bureau of Engineering Research, University of Texas at Austin, US. 29 p. Available from Internet: https://ctr.utexas.edu/wp-content/ uploads/pubs/4938_2.pdf

Bielli, M.; Caramia, M.; Carotenuto, P. 2002. Genetic algorithms in bus network optimization, Transportation Research Part C: Emerging Technologies 10(1): 19-34. https://doi.org/10.1016/S0968-090X(00)00048-6

Burns, L. D. 1979. Transportation, Temporal, and Spatial Components of Accessibility. Lexington Books. 152 p.

Cancella, H.; Mauttone, A.; Urquhart, E. M. 2015. Mathematical programming formulations for transit network design, Transportation Research Part B: Methodological 77: 17-37. https://doi.org/10.1016/j.trb.2015.03.006

Ceder, A. 2007. Public Transit Planning and Operation: Theory, Modeling and Practice. CRC Press. 644 p.

Ceder, A. 2002. Urban transit scheduling: framework, review and examples, Journal of Urban Planning and Development 128(4): 225-244.

https://doi.org/10.1061/(ASCE)0733-9488(2002)128:4(225)

Ceder, A. 2001. Operational objective functions in designing public transport routes, Journal of Advanced Transportation 35(2): 125-144. https://doi.org/10.1002/atr.5670350205

Chien, S.; Schonfeld, P. 1998. Joint optimization of a rail transit line and its feeder bus system, Journal of Advanced Transportation 32(3): 253-284.

https://doi.org/10.1002/atr.5670320302

Chien, S.; Yang, Z. 2000. Optimal feeder bus routes on irregular street networks, Journal of Advanced Transportation 34(2): 213-248. https://doi.org/10.1002/atr.5670340204

Chien, S.; Yang, Z.; Hou, E. 2001. Genetic Algorithm Approach for Transit Route Planning and Design, Journal of Transportation Engineering 127(3): 200-207. https://doi.org/10.1061/(ASCE)0733-947X(2001)127:3(200)

Coello Coello, C. A.; Lamont, G. B.; Van Veldhuizen, D. A. 2007. Evolutionary Algorithms for Solving Multi-Objective Problems. Springer. $800 \mathrm{p}$. https://doi.org/10.1007/978-0-387-36797-2

Costa, Á.; Markellos, R. N. 1997. Evaluating public transport efficiency with neural network models, Transportation Research Part C: Emerging Technologies 5(5): 301-312. https://doi.org/10.1016/S0968-090X(97)00017-X

Curtis, C. 2011. Integrating land use with public transport: the use of a discursive accessibility tool to inform metropolitan spatial planning in Perth, Transport Reviews 31(2): 179-197. https://doi.org/10.1080/01441647.2010.525330

Dalvi, M. Q.; Martin, K. M. 1976. The measurement of accessibility: some preliminary results, Transportation 5(1): 17-42. https://doi.org/10.1007/BF00165245

Desaulniers, G.; Hickman, M. D. 2007. Public transit, Handbooks in Operations Research and Management Science 14: 69-127. https://doi.org/10.1016/S0927-0507(06)14002-5

Geurs, K. T.; Ritsema van Eck, J. R. 2001. Accessibility Measures: Review and Applications. Evaluation of Accessibility Impacts of Land-Use Transportation Scenarios, and Related
Social and Economic Impact. RIVM Report 408505006. National Institute of Public Health and the Environment. Bilthoven. The Netherlands. 265 p.

Geurs, K. T.; Van Wee, B. 2004. Accessibility evaluation of land-use and transport strategies: review and research directions, Journal of Transport Geography 12(2): 127-140. https://doi.org/10.1016/j.jtrangeo.2003.10.005

Gulhan, G.; Ceylan, Hu.; Baskan, O.; Ceylan, Ha. 2014. Using potential accessibility measure for urban public transportation planning: a case study of Denizli, Turkey, Promet Traffic\&Transportation 26(2): 129-137. https://doi.org/10.7307/ptt.v26i2.1238

Gulhan, G.; Ceylan, Hu.; Özuysal, M.; Ceylan, Ha. 2013. Impact of utility-based accessibility measures on urban public transportation planning: a case study of Denizli, Turkey, Cities 32: 102-112. https://doi.org/10.1016/j.cities.2013.04.001

Hansen, W. G. 1959. How accessibility shapes land use, Journal of the American Institute of Planners 25(2): 73-76. https://doi.org/10.1080/01944365908978307

Hobeika, A. G.; Chu, C. 1979. Equilibration of supply and demand in designing bus routes for small urban areas, Transportation Research Record 730: 7-13.

Ibarra-Rojas, O. J.; Delgado, F.; Giesen, R.; Muñoz, J. C. 2015. Planning, operation, and control of bus transport systems: a literature review, Transportation Research Part B: Methodological 77: 38-75. https://doi.org/10.1016/j.trb.2015.03.002

Israeli, Y.; Ceder, A. 1995. Transit route design using scheduling and multiobjective programming techniques, Lecture Notes in Economics and Mathematical Systems 430: 56-75. https://doi.org/10.1007/978-3-642-57762-8_5

Kuah, G. K.; Perl, J. 1989. The feeder-bus network-design problem, Journal of the Operational Research Society 40(8): 751-767. https://doi.org/10.1057/palgrave.jors.0400806

Kuah, G. K.; Perl, J. 1988. Optimization of feeder bus routes and bus-stop spacing, Journal of Transportation Engineering 114(3): 341-354.

https://doi.org/10.1061/(ASCE)0733-947X(1988)114:3(341)

Lei, T. L.; Church, R. L. 2010. Mapping transit-based access: integrating GIS, routes and schedules, International Journal of Geographical Information Science 24(2): 283-304. https://doi.org/10.1080/13658810902835404

List, G. F. 1990. Toward optimal sketch-level transit service plans, Transportation Research Part B: Methodological 24(5): 325-344. https://doi.org/10.1016/0191-2615(90)90007-L

Marwah, B. R.; Umrigar, F. S.; Patnaik, S. B. 1984. optimal design of bus routes and frequencies for Ahmedabad, Transportation Research Record 994: 41-47.

Mavoa, S.; Witten, K.; McCreanor, T.; O'Sullivan, D. 2012. GIS based destination accessibility via public transit and walking in Auckland, New Zealand, Journal of Transport Geography 20(1): 15-22.

https://doi.org/10.1016/j.jtrangeo.2011.10.001

Pattnaik, S. B.; Mohan, S.; Tom, V. M. 1998. Urban bus transit route network design using genetic algorithm, Journal of Transportation Engineering 124(4): 368-375.

https://doi.org/10.1061/(ASCE)0733-947X(1998)124:4(368)

Pitot, M.; Yigitcanlar, T.; Sipe, N.; Evans, R. 2006. Land use \& public transport accessibility index (LUPTAI) tool - the development and pilot application of LUPTAI for the Gold Coast, in 29th Australasian Transport Research Forum, 27-29 September 2006, Gold Coast, Queensland, Australia, 1-18. Available from Internet: http://atrf.info/ papers/2006/2006_Pitot_Yigitcanlar_Sipe_Evans.pdf 
Ramirez, A.; Seneviratne, P. 1996. Transit route design applications using geographic information systems, Transportation Research Record: Journal of the Transportation Research Board 1557: 10-14. https://doi.org/10.3141/1557-02

Tom, V. M.; Mohan, S. 2003. Transit route network design using frequency coded genetic algorithm, Journal of Transportation Engineering 129(2): 186-195.

https://doi.org/10.1061/(ASCE)0733-947X(2003)129:2(186)

Van Nes, R.; Hamerslag, R.; Immers, B. H. 1988. Design of public transport networks, Transportation Research Record 1202: 74-83.

Wirasinghe, S. C. 1980. Nearly optimal parameters for a rail/ feeder-bus system on a rectangular grid, Transportation Research Part A: General 14(1): 33-40. https://doi.org/10.1016/0191-2607(80)90092-8

Wirasinghe, S. C.; Hurdle, V. F.; Newell, C. F. 1977. Optimal parameters for a coordinated rail and bus transit system, Transportation Science 11(4): 359-374. https://doi.org/10.1287/trsc.11.4.359

Yan, S.; Chen, H.-L. 2002. A scheduling model and a solution algorithm for inter-city bus carriers, Transportation Research Part A: Policy and Practice 36(9): 805-825. https://doi.org/10.1016/S0965-8564(01)00041-6

Yin, Y.; Miller, M.; Ceder, A. 2005. Framework for deployment planning of bus rapid transit systems, Transportation Research Record: Journal of the Transportation Research Board 1903: 11-19. https://doi.org/10.3141/1903-02 